\title{
Using Web Technologies for Supply Chain Management
}

\author{
Mărincaş Delia Adriana ${ }^{1}$ and \\ Voicilă Cristian² \\ ${ }^{1}$ Babeş-Bolyai University, \\ ${ }^{2} I T$ Quest, \\ Romania
}

\section{Introduction}

Nowadays, companies have to face global competition in order to stay on the market. In order to be competitive, they have to employ new strategies based on new technologies. Internet based Supply Chain Management is the solution that supports collaboration in the Supply Chain as the foundation for gaining competitive advantage and maintain market share. There are many Web technologies necessary for the design and implementation of a Web based SCM application, their employment being determined by the SC partners information systems and applications and the level of integration needed. Traditional technologies are considered complex and very expensive because they have to integrate heterogeneous information systems. In this chapter, we study the up to date concepts and technologies related with Internet based SCM model. We propose a new SCM model based on new Web technologies and intelligent tools to optimize the SCM application. We conclude that this model allows the design and implementation of SCM software with lower investments. Thus, Web based SCM software will be available for small and midsized companies which will have easier access to resources so that to satisfy the demand. The results will be competitivity growth, higher profits and more satisfied customers.

First section introduces the concept of Internet or Web based Supply Chain and the issues connected to this concept: management techniques, technologies, architectures from specific literature. The second and the third section present the necessary steps to follow for the design of the physical and virtual Supply Chain network. We propose an architecture for the eSCM application and a framework for its design and implementation. The last section introduces the newest Web technologies employed very recently for the optimization of SCM software, which allow the design and implementation of eSCM applications with lower costs and increased efficiency.

\section{Web based supply chain. Literature review}

A Supply Chain is a network of suppliers, manufacturers, warehouses, distributors and retailers who, through coordinated plans and activities, develop products by converting raw materials to finished goods. Supply Chain Management (SCM) involves various approaches 
used to integrate suppliers, manufacturers and distributors in performing their functions: materials procurement, materials transformation in intermediate and finished products, the distribution of these products to distribution centers and from here to point of sales and to the final customer.

The management of Supply Chain assumes to provide the appropriate strategy to deliver products and services to customers in the right quantities, to the right locations and at the right time to meet the required service level with minimal cost. Through collaboration, information sharing and usage of internal information systems and Internet technologies, companies can create efficient value systems, and get competitive advantage.

The Internet has brought new opportunities for the Supply Chain field. Companies have to adapt their Supply Chain to the Internet and to connect through Web technologies with their business partners to create Supply Chain networks. The combination of SCM (Supply Chain Management) concepts and the Internet tools resulted in a Web based application called e-SCM. E-SCM model uses Supply Chain competencies and resources and exploit them in a more efficient manner into an extended virtual organization. E-SCM applications support companies to win competitive advantage because they create more value for the customer and have the goal to satisfy the client requirements in the best possible way and in real time.

E-SCM applications allow the creation of extra value for the customer and have the goal to satisfy the client requirements in the best possible way and in real time. Migration to a web based approach for SCM applications is required for streamlining Supply Chain activities, maintaining a consistent quality of service and controlled distribution of the data which otherwise cannot be achieved.

According to Ross (Ross, 2003), SCM represents much more than these. In order to figure out its entire extent, we should approach it from three perspectives:

- tactical: SCM is an operations management technique that seeks to integrate and optimize the capabilities of internal business functions and to direct them to new opportunities for cost reduction and increased channel throughput by working with the matching functions from the Supply Chain partners, customers and suppliers. Tactical SCM can be divided in four activities: suppliers management and inventory optimization, product and service processing, customer management and customer order management, channel support activities for facilitate financial transactions, marketing information flows, electronic information transfer, integrated logistics

- strategic: SCM transforms the linear, sequential SC into a networked SC focused on functional and strategic interoperability through collaborative partnerships for the correlation of SC processes. The SC process correlation creates unique sources of value by unifying resources, competencies, capacities of the entire network (Ross, 2003).

These tactical and strategic approaches are focused on the evolution of business network, resulting in innovations, new processes and technologies, increased reliability and speed and mass customization economies.

- Web technologies: e-SCM enables the integration and synchronization of all SC information and processes. Web based applications allow the reduction of transactional costs with $80 \%$ compared to private network cost. E-commerce standards (e.g. XML, Java) enable low cost integration of customer, supplier, product information and competencies from SC partners, the transmission of documents and data in real time at every level in the Supply Chain. E-SCM generates more value for customers through the agile, flexible, collaborative intelligent systems built on dynamic networks of Web enabled partners. 
In order to implement an e-commerce system, the concept of value is important from customer's point of view, because the client generates company revenue. The value to the customer has to be considered in the moment of the creation of the e-commerce system management strategies. First, the products have to be in accordance with customers' requirements, to be available and to be accessible for them on the company sites. Customers are attracted by the products low price and high quality and value added services.

Using e-SCM applications, the value added for each product can be increased.

The Internet enables the connection of Supply Chain partners through Web technologies and allows SCM networks achieve new capabilities: real time information sharing for collaborative planning, forecasting and replenishment, visibility and management of SC event in real time, SC integration, and collaborative relationships on all levels of the network.

Collaboration allows inventory optimization, provides more value for the customer and satisfies their needs. Synchronization of processes and information from all network nodes to quickly respond to the customer needs. This is possible if customer event-driven data are available in real time across the supply network, allowing concurrent decision making while decision is transmitted in the SC system. Synchronization can provide agility and flexibility which allow to respond to changes in customer demand and supply dynamics.

eSCM applications have to centralize and manipulate data from ERP systems of SC partners trough Web technologies. They include tools for end-to-end integration of business process. The Web front end should be linked to the back-end order processing, manufacture, procurement, accounting and distribution modules included in the ERP system. Integration tools allow data access and manipulation of shared information for each Supply Chain node. These are: standards for documents transmission, access to data sources through standard database interface (e.g. ODBC), support for standard data formats (XML), application adapters to hook e-commerce packages into back-end systems, specialized business process workflow engines, business intelligence tool capable of supporting, extracting and validating data in and out of a multiple, heterogeneous system, integration and collaboration application services.

The most used method for linking back-end applications and systems for e-commerce is to provide appropriate Web interface. There are several options for this purpose: porting of Web servers on proprietary platforms, developing middletier functionality to map between browser and back-end protocols and interfacing e-commerce applications that have standard browser interfaces with back-end applications.

Usually, e-SCM business system can be divided into three components:

- $\quad$ ERP (Enterprise Resource Planning) system is the centre of present business solution. It has connected with Web-based applications to form groups of business software functions: production, purchasing, CRM, SCM. These applications have to be interconnected so that to provide complete reports on customers, demand, suppliers, supply, finance, manufacturing, delivery, etc.

- Middleware consists of e-SCM applications enabled by communication standards such as EDI and XML. Internet based standards like XML that allow quickly generation of transaction documents

- Web based applications are directly integrated with ERP backbone through EAI (Enterprise Application Integration). These applications comprises a variety of 
supplier and customer-side software applications: CRM (Customer Relationship Management) for customers management, CPC (Collaborative Product Commerce) for collaboration of manufacturing and product designers for new product development, SCM (Supply Chain Management), e-Procurement applications include exchanges to facilitate acquisition, e-Finance and Human Resources application. ESCM portals extract data from ERP system for trading partners in the Supply Chain, reducing at the same time the cost of distributing and sharing content and applications.

The e-SCM model needs that ERP systems of the partner companies and e-business applications to be integrated in order to create information flows between Supply Chain nodes. Companies have to synchronize data about customers, processes and products internally and externally. This connection needs appropriate hardware platforms and software: integration standards for document formats to enable information transfer, Internet transmission protocols as well as open data formats to facilitate data transfer between companies, standard transformation and routing tools to convert and route data in different formats, tools for creation and management of distributed business processes and document exchange, security for data transfer.

Business process logic has to be separated from applications to create the collaboration needed. EAI (Enterprise Application Integration) allows the integration of company application using a set of technologies and services that form a middleware. Technologies available for EAI are used at different levels: data level - ODBC, Java Database Connectivity, application level-CORBA, JavaBeans (EJB), Component Object Model (COM/DCOM) and business process levels - Web Service Business Processes Execution Language (WSBPEL). There are specialized SC integration technologies such as ebXML, RossetaNet developed on the basis of generic integration technologies. The above technologies provide physical integration. The logical integration includes agreements on concepts and model integration (Chandra \& Grabis, 2007). The Supply Chain middleware should provide access to data from different companies and transaction processing. When a transaction takes place, the data passes through to the middleware layer, is translated in a language like XML or Java and is sent in a readable format to another application layer.

The process oriented layer is named Business Process Management (BPM) and integrates process across business units, applications, enterprises so that to align business processes and to deliver key information. BPM provides visibility to business processes residing on different computers and architectures to support the monitoring and synchronization of business processes and events management across networked Supply Chains.

SCM portal are considered the most used applications for collaboration in the Supply Chain. Portals are front-end interfaces to enterprise information systems. Enterprises develop their own portals to provide access to company applications and Internet and intranet-based content. At the same time they can develop portals for their customers and attract them with customized services, provide intelligent information search, automatic alerting for customers using settled rules or software agents. Portals link to internal applications to retrieve data from internal data sources (ERP data), data from Web, or other vertical portals. The data should be displayed in a manner that enables decision making in a short time. The same portal can be used for different departments and business partners with controlled access and customized options. A portal for Supply 
Chain Management can provide access to company inventory in a different way for suppliers, customers and employees. The development of wireless technologies, allows enterprises to extend their portal services to their mobile users. SCM partners will be able to access the e-SCM applications through their mobile appliances: smart phones, PDAs, laptops etc.

We can conclude that the design and implementation of an eSCM application need to connect heterogeneous environments and to automate processes and data flow so that to react in a timely manner to demand changes. In order to achieve all these, numerous development tools are needed such as: programming languages, hardware and software infrastructure, IT management services, business integration for all the supply chain partners, standardization and connection of business processes for the entire chain. At the same time, transactional data from different applications and ERP systems have to be integrated, processed and sent in a standard format such as XML to the partner that needs that information. Once the data about demand, customers, orders, production, inventory, resources, supply, delivery, forecasting are available in real time to the right node in the supply chain, the managers have to make the right decisions about every strategic activity of the network and its members. This can be accomplished only by using decision support tools that use statistics and business intelligence to discover patterns in customer behaviour and market conditions and foresee the future changes and trends. In this way, companies can meet customer requirements before their competitors and gain competitive advantage.

\section{The design and Implementation of an eSCM application}

An important activity before implementing a Supply Chain information system is network design and configuration. Then relationships must me settled with partners for information exchange and performance improvement to create the suppliers and customers network. Companies must reduce the number of suppliers and select those with greater potential for collaboration in a process of supply base optimization. After designing the physical Supply Chain and the collaboration model, the SC partners should establish the network integration model so that to result a virtual organization to respond to customer requirements.

An effective Supply Chain business architecture needs to determine the best competencies in the network for each Supply Chain activity so that each function to be executed by the most appropriate company in the Supply Chain. Then, the scope of collaboration should be detailed on activities and processes for each company and the allocation of resources. In order to measure the operational effectiveness of SC and continuous growth a set of a performance measurements have to be chosen.

In the SC literature and practice, there are four basic steps we have to follow in order to design an e-SCM application:

- Internal integration of business functions for internal optimization

- External Integration of SC operations between similar functions from network members. All the processes in the Supply Chain must be designed and coordinated so that to provide agility and flexibility to adapt to customer requirements.

- Strategic collaboration with suppliers and customers for product development and order fulfilment according to customer demand through the extranet system 
- Design and implementation of a Web based application to streamline information flows and processes through collaboration

The purpose of e-SCM application architecture is to create a virtual SC network based on Web technologies. This application consists of a set of application components for crossbusiness processes that can integrate intra-enterprise and inter-enterprise business functions. This components should provide flexibility so that to able to quickly react to market changes so that to satisfy the customers in a more efficient manner. Companies need to achieve higher efficiency and increase profits, and to attain this goal, they must design and implement a Web based application for SCM. In order to justify this IT investment, the eSCM should bring significant cost reduction and revenue growth. This is not possible without an appropriate strategy.

First, the Supply Chain must be properly redesigned and then the member company information systems must be analyzed in detail. We propose a set of steps to follow in order to implement an e-SCM application. The steps we have to follow to build an e-SCM application are:

- process mapping

- internal integration of business function if this does not work through ERP systems or other applications

- value chain analysis to identify the value added sources

- collaboration settling for network design and configuration with the most important suppliers and customers: contract settling, stock management, distribution strategies, risk management, pricing, information sharing, etc.

- cost and resource management to reduce the bullwhip effect and increase profits

- external integration of business function and process standardization to achieve network integration

- $\quad$ selection of IT technologies for structuring of e-SCM application and the integration of companies information systems through e-SCM.

- design and implementation of e-SCM application

- synchronization and automation of processes and e-information flows in the Supply Chain network

- $\quad$ providing visibility of network transactions and processes to SC partners

- providing real time information about present and forecasted supply and demand

- $\quad$ e-SCM apllication has to support adaptation to marketplace and the real time response to changes in customer demand and supply dynamics.

- implementation of intelligent tools for decision making so that to provide a proactive behaviour on the market

- design and implementation of mobile version of eSCM application so that to be accessible from mobile devices

We propose an e-SCM model consisting of three modules:

1. Front-End Functions - gives static and dynamic information to the customer. In order to answer to the customer requests, these functions have to manipulate wide volumes of data. $\mathrm{XML}$ is used to integrate Web and server-based components and to pass information between EAI middleware servers and back-end databases. An important component here is customer module which allows order management, order track and trace, customer service, inventory reports, customers' management. 
2. Middleware Functions - the front-end passes the external request for further processing to the middleware application servers. The logic processing is mostly executed at this level.

- middleware SCM: order management, CPFR, production planning, replenishment management, delivery management, SC coordination and scheduling, decision support tools that uses analytics and artificial intelligence techniques such as multiagent systems. Agents provide the automation of replenishment, production tracking, orders fulfilment, event management.

3. Back-End Functions. Company information system or ERP system executes transactions processing, support all departments within an enterprise and manages internal and external resources including tangible assets, financial resources, materials, and human resources. The hardware should allow support for dynamic applications, scalability and flexibility.

The ERP system can include software for manufacturing, order entry, accounts receivable and payable, general ledger, purchasing, warehousing, transportation and human resources. ERP facilitates the flow of information between all business functions inside the boundaries of the organization and manage the connections to outside partners. It provides data to support the core business functions of the organisation including production, distribution, Supply Chain, financials and customer relationship management.

A basic e-SCM system should manage orders, production, purchasing, delivery to get the needed data so that to be able to synchronize the activities in the Supply Chain. The application should first be a Web based portal for information sharing, transaction execution and process synchronization with business partners, concerning demand, production and supply in real time.

This application should then be developed to integrate the components of the information systems of business partners and their applications, so that to automate the activities in the Supply Chain network under a common Web interface. Business processes automation involves process synchronization and integration.

Supply Chain members can dynamically interact and initiate business processes in the information system of its partner through predefining business rules first and then they can trigger events along the systems using eSCM application. This means that physical Supply Chain can become at least partially automated. Automation frees staff from routine work and they can monitor the system to improve it by including their experience and knowledge in application knowledge and rule database. They can involve in planning Supply Chain strategy to increase processes efficiency and.

The model can be extended to employ components for wireless usage that brings many advantages: allows SC applications to transmit real time data from the field, customer demand information is available in real time, employees can share information about activities and processes in the SC. Wireless technologies allow data access for collaborative information exchange and for tracking the position of items in the SC: RFID (Radio Frequency Identification) technology allows the real-time posting of data by mobile operators so that to identify products location in the Supply Chain network.

The architecture we proposed for ESCM, is based on traditional model for the Web based Supply Chain. In order to design and implement the model, the partner companies should invest substantial amount of money. However, new web technologies have arisen: Software as a Service (SaaS), Platform as a Service (PaaS) and Infrastructure as a Service (IaaS). These Internet based services should be deployed to outsource common competencies for the members of SC, because they provide common standardized infrastructure, platforms and software services, at a lower price and higher quality. At the same time these technologies 


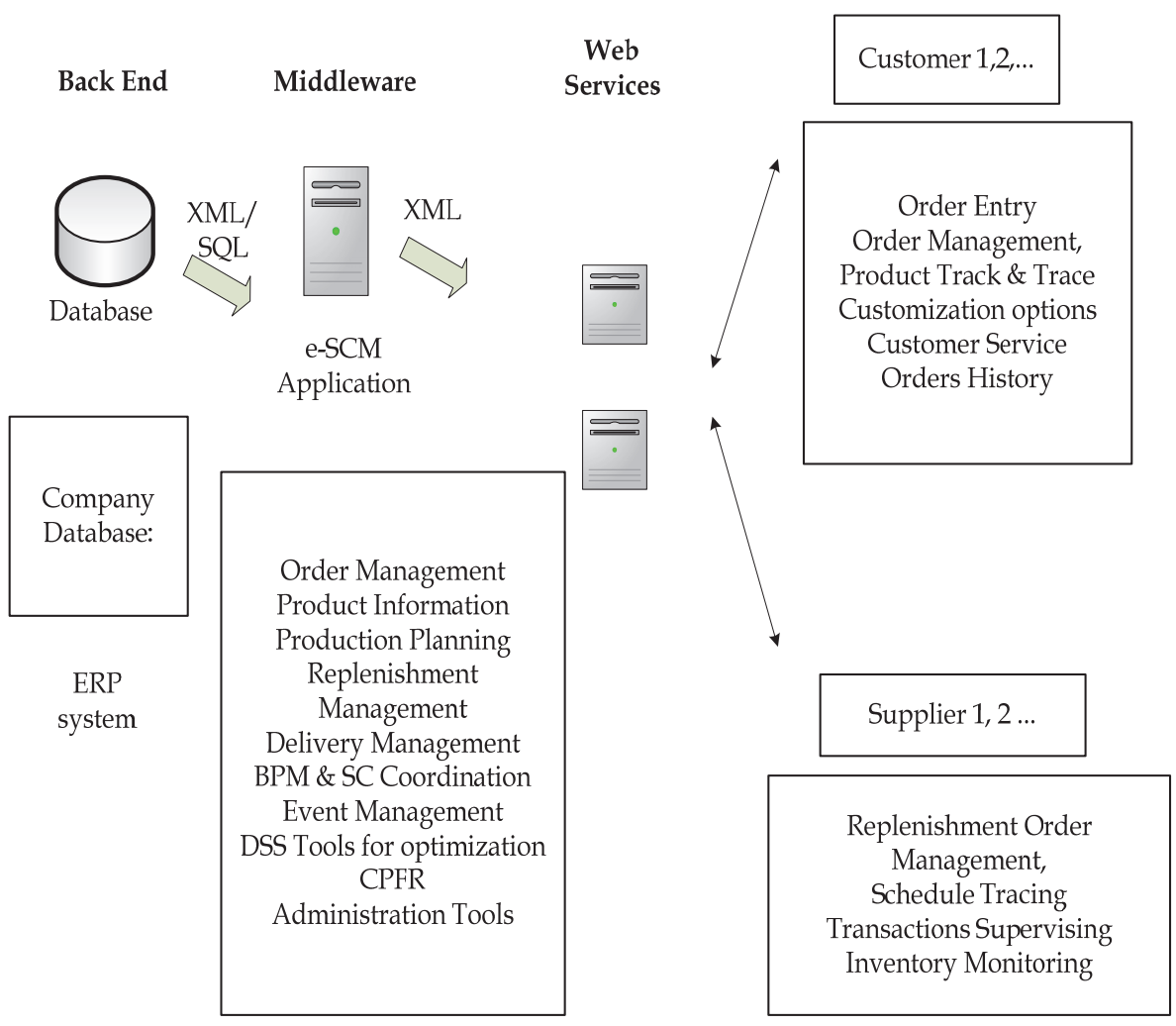

Fig. 1. The eSCM architecture 
allow the creation of a dynamic network which can share information and resources in a very effective manner. Thus, the managers can make faster and better decisions based on real and accurate data to react to volatile markets and demand.

In the next chapter we will propose an agent based framework for decision support to automate and streamline the activities in the SC network. The last section presents the future developments of the proposed models to implement the new SaaS technologies.

\section{Multiagent framework for eSCM application}

Many technologies were used to automate and streamline SCM activities, but they could not provide enough flexibility to react in real time to market events. In this context, we use agent technology as an appropriate solution for designing Web enabled Supply Chain software, because it shows many of the characteristics a SCM system should have: autonomy, collaboration, proactiveness, adaptability, mobility (Moyaux, 2006). The model we propose intends to solve the problem of automating activities in eSCM for searching, manufacturing, scheduling, exception report, etc. in real time without or with a limited human intervention. The purpose is to manage real time information, events and demand faster, more effective and in a coordinated manner so that to synchronize the entire Supply Chain (Simchi Levi et al, 2008).

Software agents are autonomous program units supported by an execution environment. Software agents can use the network to send themselves to other processors, thus "moving " around computers. Control system can benefit from agent technology in many ways. Modularity is the key for a control system and the property key of an agent system. Autonomy is another characteristic of agents that allows the user to accomplish the task. Proactive agents take initiative and change their environment, for example, once an agent has completed its task on a machine or is unable to do it, the agent migrates.

Creation of the service agent: the directory agent is running as a part of a system agent pool and this must create it on the agent execution environment :

- Sign in: each agent will register itself with following parameters: agent name and service agent address. The agent also signs in to the core service for each transaction that occurs between local and the central core service. This ensures location independence.

- Sign off: gent informs core service when his jobs are done or some information need to be transferred from service core database to the agent. When the jobs are finished the core service automatically will sign off the agent. Also, another problem which can occur during the authentication or the data transfer between the agent and the core is the network disruption which are checked by the core service which automatically will sign off the agent.

- Query: Every agent installed on the local or different network and authenticated to the core service can query the service.

- Cache: Each transaction in an agent execution environment will be kept in the tracking collection.

Analyzing these processes yields that there are two kinds of channel that are used to communicate within the environment with the core service system: The first one is the "Internal channel" and the second one is the "External Chanel". The Internal channel is used for any transactions among agents and the core service in the agent execution 
environment. The External Channel is used in order to communicate among directory service agents.

Advantages of applying the agent technology to a distributed core service :

- Reliability: transforming core system from a monolithic system into a parallel system

- Versatility: Each system is able to access the remote core system and not every system can be fault-tolerant in their core

- Integration: This kind of system are much easier to integrate, the results derives directly from the characteristics of the agent architecture

- $\quad$ Remote access: The core system can be controlled remotely via LAN, WAN, etc.

- Security: A good solution to secure network security is to use a private or virtual network system which can prevent unauthorized personnel.

- Dependability: although the reliability of the system grows in term of fault tolerance and fault recovery it is necessary to determine the scheme of trade-off of the network which are simple because are based on availability of the network structure.

The only disadvantage of the core system with agents is the network availability.

The agent technologies are necessary to be developed and employed in SCM applications so that to replace humans for routine and even for complex tasks. We consider that multiagent systems together with web technologies can automate, connect and optimize SC processes.

The processes and operations can be automated by using intelligent agents not only for one company or one tier, but for the whole SC network. As we can see in the figure, the relationships can be extended from the manufacturer to the $2^{\text {nd }}$ tier suppliers and raw materials suppliers. Once an order arrives, the manufacturer can send the purchasing orders directly to the $2^{\text {nd }}$ and $3^{\text {rd }}$ tier suppliers so that to quicken the whole purchasing process, eliminating intermediates. The agents can communicate to each other to manage operations, events and exceptions for every tier in the SC.

The proposed agent framework is designed for the automation of routine activities in the Supply Chain: order management, replenishment, inventory management, production, delivery, event management, and analytics. These agents manage the activities and optimize them so that to reduce costs, allocate resources efficiently, and streamline processes and information flows on the first tier of the Supply Chain. This architecture includes agents for communication, connection to database sources and servers and connection between application components. Company databases are managed by mySQL server, services are executed by intelligent agents built with Java. PostgreSQL was employed to provide for concurrent access to company databases so that to automate services and at the same time to allow human intervention and control. Open source software allows cutting costs with software acquisition and maintaining.

Customers are ordering products through the company site. They can choose the standard products or they can configure their own customized products. After the client registers with the company site, he places the order; the order is sent to the eSCM middleware and validated by the company employee. If the product is on stock, an invoice is generated, the payment date is set. After receiving the payment, the ordered product is delivered to the customer and the order is fulfilled. If the product is not on stock, a supply order is sent to the suppliers having the best price for the product. Usually companies have agreements on prices and quantities and a list of suppliers they use to work with. If none of the suppliers can deliver the product at the right time and price, the agent will search for another supplier on the Internet. Depending on the result, the employee managing replenishment will decide 


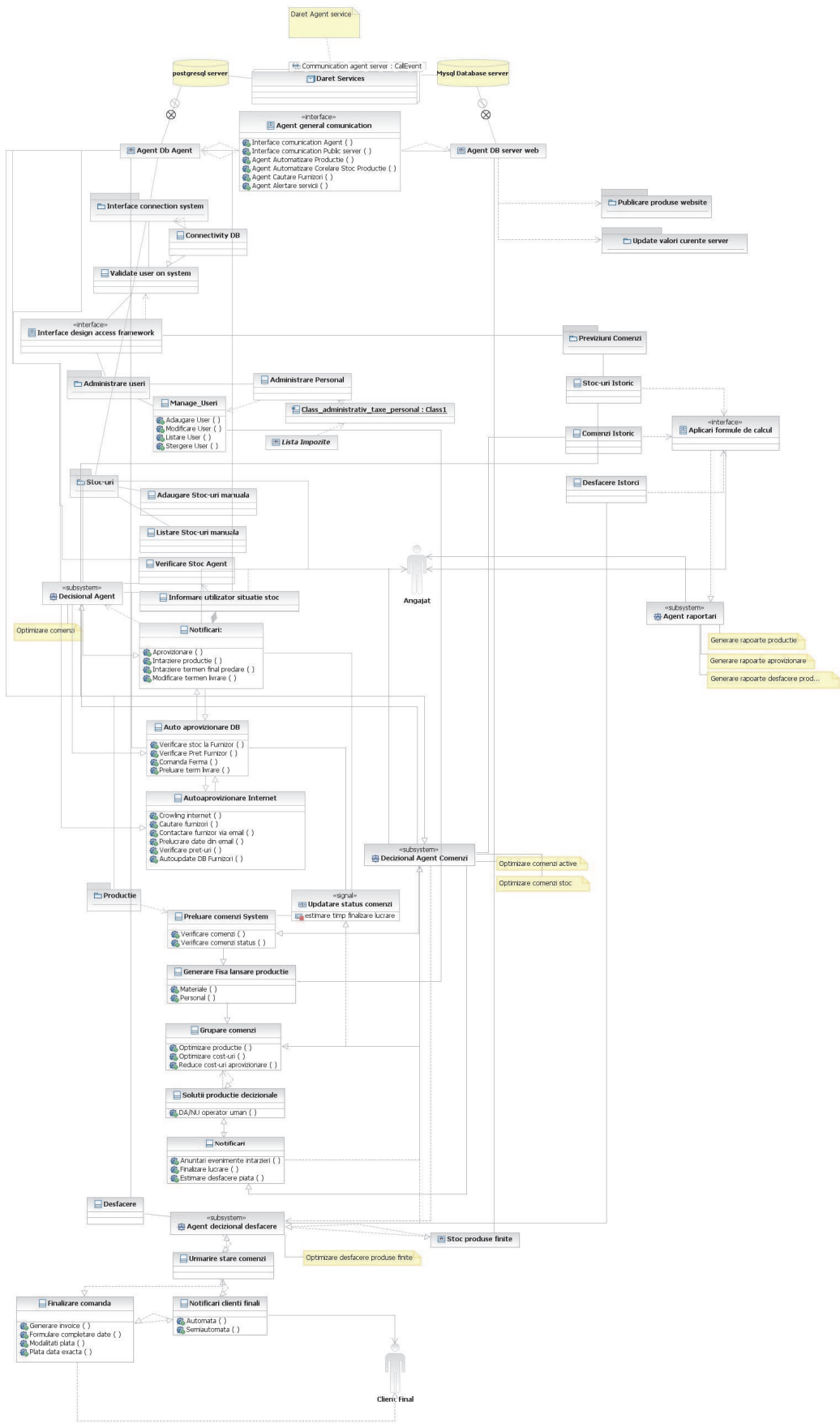

Fig. 2. Multiagent framework for eSCM application 
on the supplier and will send an order to fulfil the order. If there is no supplier to deliver the product according to the client requirements, the order will be cancelled.

If the order needs to manufacture a customized product, the decision agent will generate the bill of materials and check the stock for the raw materials and components needed. If they are not on stock, the agent will trigger replenishment process in a similar way as in the product replenishment case. If the product cannot be manufacture in the due time, the agent will send messages to the customer to announce him about the delay. All the data about orders, production, and replenishment status are automatically updated and showed through eSCM application.

The agent can group the orders so that to order the same product just once but in higher quantities, if possible. Production is optimized also to use the resources to manufacture more similar products at the same time. Delivery is optimized through product shipment in lots or groups of products to the same destination or area. All these lead to cost reduction and significant increase in profits.

The application has a special module for customers so that they can manage orders, track and trace order status, order history, customer profile. This is an efficient tool to provide personalized interaction with the customer and to obtain customer profile which allows market segmentation and better satisfaction of clients' requirements.

Agents will send exception messages every time an unforeseen event is taking place and will update the information about items involved in this problem for the entire eSCM application: order management module, manufacturing and replenishment, customer module, etc.

The SC activities are automated by intelligent agents but the human user can interfere in the process and can take different decision if they consider to be more appropriate. In this way the system can be supervised and optimized by employees who are not busy to execute routine activities that are now being automated by means of agents. After the implementation of the system the application can be improved with specific observations from experts so that to achieve a higher efficiency.

This model automates the SC processes activities inside and outside company boundaries. The model will be extended so that to include new Web services based on cloud computing, such as SaaS, PaaS, IaaS. The new service oriented Internet tools allow cross-company teams to interconnect data and information through common shared applications so that to form collaborative Supply Chain nodes which integrate processes to optimize the Supply Chain network activity. The goal is to access resources and business partners, to manage them efficiently following a customer-centric strategy. Companies compete with the price, product, service quality, information services and e-business connection. For this reason, we will analyze in the next chapter how our model can be extended to include these service oriented Web technologies.

\section{Cloud computing for supply chain management}

Cloud computing supplies computational resources on demand via a computer network (Wikipedia). Traditional computing models require both data and software to be fully contained on the user's computer. In cloud computing, the user's computer may contain almost no software or data (only an operating system and a web browser). The provider's cloud computing services form the cloud. These services are provided via an Internet connection within one or more of the next layers: application, platform and infrastructure. 
- Application services (SaaS- Software as a Service) deliver software as a service over the Internet to the client who doesn't need to install and run the application on his own computers. All the software management, update, maintenance and support are executed centralized, only on the provider's computers. The software allows collaboration through the network with business partners due to its model - single instance, multi-tenant architecture.

- Platform as a Service provides a computing platform comprise hardware architecture and software framework to support the software.

- Infrastructure as a Service (IaaS) provides computer infrastructure as a service: servers with multi-core processors, software, data-center space or network equipment.

Companies can use one or combinations of these services and they pay according to the payfor-what-you-use model, achieving significant cost reductions. The service provider will deal with investment in licenses, infrastructure maintenance and upgrades. Software implementation is simple, with minimal technical requirements and easy management.

Cloud computing is an innovative business model which ensures an efficient outsourcing for Supply Chain collaboration software and infrastructure. We will prove the advantages of using cloud computing technology for SCM.

The Supply Chain and the cloud have similar features: are distributed, shared and dynamic, adapted their size, structure and functionality to support their business environment. Collaboration is supported by company software but is very expensive to implement due to the heterogeneous environment that must be connected. Cloud based centrally-hosted software is a cheaper and more efficient solution, providing cost and risk reduction and access to new technologies for better scalability and security.. Compared to the substantial investments in collaboration services required by traditional SCM models, Cloud computing reduces the cost of collaboration for SCM. The Cloud is considered a flexible, cost-effective pricing structure. Another advantage is remote implementation, customization, and integration, without additional investments. Despite huge investments needed for end-toend integration of traditional Supply Chain, cloud is an affordable technology for small and midsize manufacturers.

SCM business processes are parallel and data are managed by each company's integrated information system. In order to extend these internal systems to SC level, companies have to connect them through networks. Cloud computing enables the networking of multiple and interdependent end-to-end processes (order fulfilment, collaborative forecasting and replenishment, market analysis). It supplies a collaborative framework allowing an effective process management through standardized processes.

SaaS provides a high level of security, so that company are able to share information without trust limitations. This creates visibility for each Supply Chain member for the entire network o that to support the decisional process.

Traditional systems don't have the flexibility and elasticity needed to scale computing infrastructure demanded by Supply Chain networks. Products, processes, demand, technologies and partners are continuously changing and Cloud computing can adapt to every type of user and to the strategy of the entire Supply Chain network (Singh, 2011).

Elasticity allows partners to change or switch applications with minimal cost. Thus, companies can launch new products or services or enter new markets.

Cloud computing enables the SC network to work on a single platform. SC members have a single view for all the processes and activities in their network. Thus, cloud technologies provide an efficient decision support tool which adapt to market changes and increase profits for each participant in the Cloud based SC. 
The Supply Chain network can work with any supplier to match the needs of the customer without constraints. Thus, due to the advantages of cloud computing, companies reduce costs (such as total cost of ownership), reduce working capital, launch innovative products to market faster, work more effective, adapt to market changes and better satisfy the customer needs.

We will extend this e-SCM model to include cloud computing facilities which provide a cheaper and more standardized infrastructure, more resources available for Supply Chain partners. The eSCM application have to be redesigned so that company ERP system to work inside company premises and at the same time to send real time data for eSCM components working in the Cloud to provide outsourced services. The Cloud based eSCM application will support complex processes between multiple partners and will increase sensitive reactions to market changes. The Supply Chain activities outsourced with the Cloud are those which don't need much customization:

- planning and forecasting

- logistics: inventory and transportation management, network strategy, warehousing, replenishment, order processing. For example, inventory tracking can be performed by asking suppliers to report into the cloud about the components shipment and their current status. This will allow a better planning and scheduling to fulfil the orders in due time and answer to customer needs.

- $\quad$ sourcing \& procurement: for supplier management, contract management.

- $\quad$ service and spare parts management and distribution, reverse logistics processing.

- $\quad$ sales: for mobile facilities and more customers

Cloud Computing moves computing from the desktop to remote computers. Different computing devices such as PCs, handheld devices and cell phones connect to remote computers through wired or wireless connections. This service is an operational expenditure, so companies can afford these investments in cloud technologies.

In order to operate efficiently, Supply Chains need a real time exchange of knowledge and the ability to collaborate with their partners to manage events in real time. This is possible with the cloud as it provides these facilities for each type of business.

Manufacturing processes will benefit too from cloud computing, because real time information sharing and synchronization allows and agile and flexible production so that to react faster to demand and supply changes. Sales Forces will be the first users of cloud computing followed by CRM, Human Resource Management and email services.

Cloud computing will reduce transaction cost for trading partners. Transaction costs grow with the business growth. The cloud based eSCM application will adapt to supply-chain needs concerning collaboration and visibility, support for managing a dynamic and constantly changing network.

Companies don't want to replace their ERP system with new cloud computing applications due to the need for sharing information and trust problems. However, they will use a mix of on-premise, public cloud and private cloud based applications, depending on their dimensions of the company and Supply Chain needs. The concept of private cloud computing allow companies deploy technologies such as virtualisation and multi-tenant applications to create their own "private cloud" data centres. The public cloud will have more success for providing visibility in collaborative activities between partners. The company can make decision having the needed data in real time from the cloud. In order for this cloud based eSCM application to work, companies need to settle agreements to be able to share information without having trust problems so that to be able to collaborate. 
We conclude that the e-SCM prototype model we proposed is based on classical and new technologies which are an appropriate approach for nowadays business trends and economic crisis. Once designed and developed, the e-SCM model can be extended and improved by adding new facilities based on new technologies available on the IT market.

Our contribution to SCM research is the study of Web based Supply Chain trends and the optimization proposals through Web technologies and intelligent tools. We consider that the convergence of traditional information system and new Web technologies is achievable with the purpose of solving Supply Chain problems. As a result we will obtain a virtual Supply Chain based on the best technologies capable of managing the physical Supply Chain in an efficient manner. The result will be more added values for the client and higher profits for the entire Supply Chain network. Another useful result of our research is the possibility of providing SCM applications with lower investments due to new cloud computing technologies. eSCM software becomes available for small and midsized companies which become more competitive, thereby better satisfying the customer.

In our future work we will optimize the design and implementation of eSCM application by using the most efficient methods and technologies, both traditional and modern. Our purpose is to be able to provide a Web based framework that meets the collaboration requirements of small and medium size companies. This framework will allow real time collaboration through the Internet for every type of company, regardless its size or domain, so that to be able to stay on the market even during crisis periods and increase profits.

\section{Conclusion}

Web based SCM is a complex issue and needs to be approached taking into consideration the need for collaboration in the global economy and the possibility of implementation. Traditional solutions are considered to be complex and very expensive. We have proposed a model based on old and new technologies which can make eSCM application available for small and midsized companies, with lower investments. This provides the possibility to access expensive resources and new business partners so that they become more efficient, can better satisfy the changing customer requirements and increase profits.

\section{References}

Ross, F. (2003), Introduction to e-Supply Chain Management, engaging Technology to Build Market Winning Business Partnerships, St. Lucie Press, ISBN 1-57444-324-0, Boca Raton, USA

Chandra, C., Grabis, J. (2007), Supply Chain Configuration. Concepts, Solutions and Applications, Springer Science and Business Media, ISBN 978-0-387-25190-1, New York, USA

Simchi-Levi, D., Kaminsky, P. \& Simchi-Levi, E. (2008), Designing and Managing the Supply Chain, Concepts, Strategies and Case Studies, McGraw-Hill, ISBN 978-0-07-2982398, New York, USA

Moyaux, T., Chaib-draa, B. \& Muller., J., Supply Chain Management and Multi agent Systems: An Overview,15.07.2010, Available from www.citeseerx.ist.psu.edu.

Wikipedia, 01/03/2011, Available from http://en.wikipedia.org/wiki/Cloud_computing 
Singh, A. (March, 2011), Cloud Computing for Supply Chain Solutions. The case for leveraging the Cloud to run your supply chain, in Supply\&Demand Chain, 20.03.2011, Available from

http://www.sdcexec.com/publication/arti

cle.jsp?pubId=1\&id=11986\&pageNum=1 


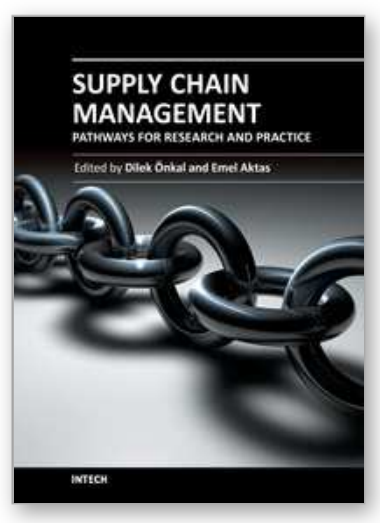

\author{
Supply Chain Management - Pathways for Research and Practice \\ Edited by Prof. Dilek Onkal
}

ISBN 978-953-307-294-4

Hard cover, 234 pages

Publisher InTech

Published online 01, August, 2011

Published in print edition August, 2011

Challenges faced by supply chains appear to be growing exponentially under the demands of increasingly complex business environments confronting the decision makers. The world we live in now operates under interconnected economies that put extra pressure on supply chains to fulfil ever-demanding customer preferences. Relative attractiveness of manufacturing as well as consumption locations changes very rapidly, which in consequence alters the economies of large scale production. Coupled with the recent economic swings, supply chains in every country are obliged to survive with substantially squeezed margins. In this book, we tried to compile a selection of papers focusing on a wide range of problems in the supply chain domain. Each chapter offers important insights into understanding these problems as well as approaches to attaining effective solutions.

\title{
How to reference
}

In order to correctly reference this scholarly work, feel free to copy and paste the following:

Mărincaş Delia Adriana and Voicilă Cristian (2011). Using Web Technologies for Supply Chain Management, Supply Chain Management - Pathways for Research and Practice, Prof. Dilek Onkal (Ed.), ISBN: 978-953-307294-4, InTech, Available from: http://www.intechopen.com/books/supply-chain-management-pathways-forresearch-and-practice/using-web-technologies-for-supply-chain-management

\section{INTECH}

open science | open minds

\author{
InTech Europe \\ University Campus STeP Ri \\ Slavka Krautzeka 83/A \\ 51000 Rijeka, Croatia \\ Phone: +385 (51) 770447 \\ Fax: +385 (51) 686166 \\ www.intechopen.com
}

\author{
InTech China \\ Unit 405, Office Block, Hotel Equatorial Shanghai \\ No.65, Yan An Road (West), Shanghai, 200040, China \\ 中国上海市延安西路65号上海国际贵都大饭店办公楼405单元 \\ Phone: +86-21-62489820 \\ Fax: +86-21-62489821
}


(C) 2011 The Author(s). Licensee IntechOpen. This chapter is distributed under the terms of the Creative Commons Attribution-NonCommercialShareAlike-3.0 License, which permits use, distribution and reproduction for non-commercial purposes, provided the original is properly cited and derivative works building on this content are distributed under the same license. 